\title{
Screening and Characterization of Lactobacillus casei MCL Strain Exhibiting Immunomodulation Activity
}

\author{
Jae Kyoung Choi, Yea-Seul Lim, Hee-Jin Kim, Yeong Ho Hong, Buom-Yong Ryu, and Geun-Bae Kim* \\ Department of Animal Science and Technology, Chung-Ang University, Anseong 456-756, Korea
}

\begin{abstract}
As an appraisal for the application of a new starter culture, more than 200 lactic acid bacteria strains were isolated from raw milk and healthy human feces. The strains showing excellent growth and acid production ability in $10 \%$ skim milk media were selected and identified as Lactobacillus casei based on the results of their API carbohydrate fermentation patterns, as well as $16 \mathrm{~S}$ rDNA sequence analysis. To assess the effect of $L$. casei strains on irritable bowel disease (IBD), the inhibitory effect of the selected strains against the nitric oxide (NO) production of lipopolysaccharide (LPS)-stimulated RAW 264.7 cells was measured. Among the tested L. casei strains, L. casei MCL was observed to have the greatest NO inhibitory activity. Additionally, L. casei MCL was found to inhibit mRNA expression of pro-inflammatory cytokines (interleukin-1 $\beta$, IL-6, TNF- $\alpha$ ), as well as cyclooxygenase-2 (COX-2) and inducible nitric oxide synthase (iNOS) involved in pathophysiologic processes such as inflammation. The mRNA expression of anti-inflammatory cytokines, including IL10 and transforming growth factor- $\beta$ (TGF- $\beta$ ) of $L$. case $i$ MCL, was confirmed using quantitative real-time PCR. In conclusion, L. casei MCL showed decreases in the expression of pro-inflammatory cytokines and up-regulated expression of the anti-inflammatory cytokine.
\end{abstract}

Key words: immunomodulating, Lactobacillus casei, probiotics, cytokine

\section{Introduction}

As it is a well-established fact that many gastrointestinal disorders are associated with changes in the intestinal mucosal function and the stability of the intestinal microflora by probiotics, it would be interesting to determine whether fermented milk products containing probiotics could serve as a new functional food to confer health care benefits. Probiotics can be defined as "live microbial food ingredients that, when administered in adequate amounts, confer a health benefit on a host" (FAO/WHO, 2001). Since lactic acid-producing bacteria confer various advantageous effects by improving the ecosystem in the gut, they are referred to as probiotics.

Lactic acid bacteria are widely used as probiotic microorganisms because of the health and nutritional benefits contributed to the host, such as maintaining the balance of the intestinal microflora, lowering of serum cholesterol, and enhancement of immunopotentiating activity and $\gamma$ -

*Corresponding author: Geun-Bae Kim, Department of Animal Science and Technology, Chung-Ang University, Anseong 456756, Korea. Tel: 82-31-670-3027, Fax: 82-31-676-5986, E-mail: kimgeun@cau.ac.kr aminobutyric acid (GABA) production (Fuller, 1993; Gilliland and Walker, 1990; Sanders, 1993). In addition, a variety of convincing evidence regarding the anti-inflammatory properties of probiotics has been proposed by many studies (Lee et al., 2008; Menard et al., 2004). Among the probiotics, $L$. casei strains may be isolated from raw or fermented dairy products, gastrointestinal tracts, and the reproductive systems of humans and animals, as well as fermented plant products (Kandler and Weiss, 1986). The L. casei YIT 9029 strain is a typical common probiotic, the immune modulation activities of which have been studied extensively (de Waard et al., 2001; Kato et al., 1984; Matsumoto et al., 2005; Matsubuchi et al., 2003). This strain has yielded beneficial results in clinical trials with bladder cancer patients (Kakizoe, 2000) and has been shown to prevent atypia in colorectal tumors, although the exact mechanism of prevention has yet to be elucidated (Ishijawa et al., 2005).

Inflammation occurs when the host's immune system attempts to counteract injurious agents such as invading pathogens (Henderson et al., 1996; Ulevitch and Tobias, 1995). The immunoregulatory mechanisms that include regulatory cells, cytokines, and apoptosis, among others, contribute in controlling immune responses by preventing 
pathologic infection associated with excessive reactivity. The lack of these mechanisms results in many inflammatory diseases such as inflammatory bowel diseases (IBDs). The production of cytokines triggered by bacterial components such as lipopolysaccharide (LPS), lipoteichoic acid (LTA) and peptidoglycan can lead to the development of systemic inflammatory response syndrome. LPS activates the cells of the innate immune system to produce a variety of inflammatory cytokines such as interleukin-1 (IL-1), IL-6, IL-8, TNF- $\alpha$, and NO (Wai et al., 2004). Nitric oxide (NO) is highly reactive molecule generated endogenously from L-arginine by a family of NO synthase (NOS) isoenzymes (Coleman, 2001). The isoenzyme present in macrophage is an inducible form (iNOS), able to produce high concentrations to NO in many cells after stimulation with bacterial endotoxins, LPS or different proinflammatory cytokines including TNF- $\alpha$, IFN- $\gamma$, IL-1, IL-6, etc (Nathan, 1994; Stuehr and Marlette, 1985; Stuehr and Marlette, 1987). Among several inflammatory diseases, IBDs are closely connected with lactic acid bacteria (Lee et al., 2008). IBD patients may suffer from abdominal pain, diarrhea, intestinal obstruction, and/or bloody stool. To date, therapies such as anti-inflammatory drugs, steroids, or anti-tumor necrosis factor can effectively reduce the symptoms and signs associated with IBD, while there remains no known medical cure for IBD (Hanauer, 2002; Macdonald and Monteleone, 2005).

Therefore, the NO inhibitory ability and cytokine profile of $L$. casei strains were assessed in this study in order to determine the immunomodulating potential of $L$. casei strains.

\section{Materials and methods}

\section{Identification of $\boldsymbol{L}$. casei MCL}

The bacterial 16S rRNA gene was amplified by PCR using the HotStarTaq ${ }^{\circledR}$ Plus Master Mix Kit (Qiagen, USA) containing DNA polymerase, dNTPs, Tris- $\mathrm{HCl}$ (pH 9.0), $\mathrm{KCl}, \mathrm{MgCl}_{2}$, and primers pBact27F (5'-AGAGTTTGATCMTGGCTCAG-3') and pUniv 1492R (5'-GGYTACCTTGTTACG ACTT-3') (Lane, 1991). The PCR product was purified using a PCR purification kit (Qiagen, USA). Gene cloning, DNA transformations using E. coli, DNA manipulations, and agarose gel electrophoresis were performed as reported by Sambrook et al. (1989). The 16S rRNA gene was sequenced at Solgent Corp. (Korea).

Carbohydrate fermentation patterns were measured using an API 50 CHL carbohydrate test kit (bioMerieux Co., France). Briefly, bacteria were cultured in de Man,
Rogosa and Sharpe (MRS) broth (Difco, USA) at $37^{\circ} \mathrm{C}$ for $12 \mathrm{~h}$ and centrifuged at $17,940 \mathrm{~g}$ for $10 \mathrm{~min}$. After centrifugation, the cells were washed twice in 1X PBS buffer. Turbidity was assessed using the McFarland Standard 4 , and $3 \mathrm{~mL}$ of the diluted sample was inoculated into API $50 \mathrm{CHL}$ medium. Subsequently, $100 \mu \mathrm{L}$ of sample were inoculated into each API test well containing 49 different carbohydrates. The fermentation profiles were confirmed by the manufacturer's API web site (https:// apiweb.biomerieux.com).

\section{Culture characteristics in skim milk}

L. casei MCL isolated from raw milk and L. casei YIT 9029 obtained from Korea Yakult Co. were tested for their viable cell count, $\mathrm{pH}$, and acidimetry. To measure the viable cell count, cells were cultured in MRS broth twice and inoculated in $10 \%$ skim milk supplemented with $2 \%$ glucose. Cells were counted at an interval of $4 \mathrm{~h}$ for a total of $36 \mathrm{~h}$. Cultured cells were diluted in anaerobic dilution solution and applied to MRS agar. The plates were cultured in an incubator for $48 \mathrm{~h}$ at $37^{\circ} \mathrm{C}$. The $\mathrm{pH}$ was tested using a pH meter (M530P, Nova Analytics Corp., USA).

\section{Preparation of bacterial components for nitric oxide assay}

LAB were cultured in MRS broth at $37^{\circ} \mathrm{C}$ for $12 \mathrm{~h}$ and harvested by centrifugation at $10,000 \mathrm{~g}$ for $15 \mathrm{~min}$. After bacterial cells were washed twice with $1 \times \mathrm{PBS}$ buffer, samples were heated at $100^{\circ} \mathrm{C}$ for $10 \mathrm{~min}$ and centrifuged at $10,000 \mathrm{~g}$ for $30 \mathrm{~min}$ and the supernatant was used for the NO assay after filtration.

The strains grown in skim milk medium at $37^{\circ} \mathrm{C}$ for 24 $\mathrm{h}$ and were heated at $100^{\circ} \mathrm{C}$ for $10 \mathrm{~min}$ and centrifuged at $10,000 \mathrm{~g}$ for $30 \mathrm{~min}$.

\section{Cell culture}

RAW 264.7 cells obtained from the Korean Cell Line Bank (Seoul, Korea) were cultured in Dulbecco's modified Eagle's medium (DMEM) with 10\% fetal bovine serum (FBS) and 1\% $100 \mathrm{U} / \mathrm{mg}$ penicillin/streptomycin. All cultures were incubated at $37^{\circ} \mathrm{C}$ in a humidified atmosphere with $5 \% \mathrm{CO}_{2}$. The cell number and viability were assessed by Trypan blue dye exclusion on a Neubauer hemocytometer. Cells were cultured to confluence in sterile tissue culture dishes and gently detached by repeated pipetting. For the experiments, cells were cultured in triplicate at a density of $5 \times 10^{5}$ in 24 -well tissue culture plates (Nunc, Denmark). Cell cultures were incubated for $24 \mathrm{~h}$ 
and analyzed for NO concentration.

\section{Nitric oxide assay}

To assess the NO production-inhibitory activity of $L$. casei MCL, the RAW 264.7 cells $\left(1 \times 10^{6} / \mathrm{mL}\right)$ previously cultured in DMEM were stimulated for $24 \mathrm{~h}$ using LPS ( $50 \mathrm{ng} / \mathrm{mL}$ ) and $10 \%$ of LAB fractions (the supernatant of bacterial cell suspension or skim milk culture). The concentration of $\mathrm{NO}$ was determined by measuring the amount of nitrite in the cell culture supernatant using Griess reagent (Sigma, USA) according to the manufacturer's protocol. The cultured RAW 264.7 cells were briefly centrifuged at $1,000 \mathrm{~g}$ for $10 \mathrm{~min}$, with $150 \mu \mathrm{L}$ of the cell culture supernatant mixed with $150 \mu \mathrm{L}$ of Griess reagent and subsequently incubated for $10 \mathrm{~min}$ at room temperature. The absorbance was measured using a microplate reader at $540 \mathrm{~nm}$ and compared to a calibration curve generated using sodium nitrite as a standard.

\section{Preparation of cDNA and real-time PCR}

Total RNA was collected from stimulated RAW 264.7 cells using TRIzol reagent (Invitrogen, USA), as described by the manufacturer's protocol. RNA was further isolated using the RNeasy Mini Kit from Qiagen (USA), in accordance with the manufacturer's protocol. The remaining DNA in the extract solution was removed with the DNase I kit (Ambion, USA), and cDNA was synthesized using SuperScript III (Invitrogen, USA). The concentration of cDNA was measured using a NanoDrop spectrophotometer (Thermo Scientific, USA) and adjusted to $100 \mathrm{ng} / \mu \mathrm{L}$.
The expression of selected cytokines in RAW 264.7 cells exposed to $L$. casei MCL cellular components and skim milk cultures was determined by real-time quantitative PCR using SYBR Green technology with the ABI 7900HT (Applied Biosystems, USA). Primers used for the PCR included glyceraldehydes-3-phosphate dehydrogenase (GAPDH), COX-2, iNOS, TNF- $\alpha$, IL-1 $\beta$, IL-6, IL10 , and TGF- $\beta$, and the cDNA sequences were obtained from GenBank with accession numbers XM_124295.1, NM_000963, NM_010927, XM_123058.1, NM_008361.3, NM_031168.1, NM_010548.2, NM_011577.1, respectively. The nucleotide sequences of the primers and probes are shown in Table 1.

\section{Statistical analysis}

All samples were measured in triplicate. Statistical analyses were performed using SPSS 18.0 (SPSS for windows, USA). The results of cytokine expression are analyzed by one way ANOVA followed by Turkey's multiple comparisons test. All samples were considered statistically significant at $p<0.05$.

\section{Result and Discussion}

Identification and DNA sequencing of $L$. casei MCL

The strain MCL isolated from raw milk was a catalase negative, non-motile, gram-positive, rod-shaped bacterium. Most of these features are characteristic of the genus Lactobacillus. Biochemical and molecular biological identification were attempted. Carbohydrate fermenta-

Table 1. Primer sequences used for real-time PCR analysis

\begin{tabular}{|c|c|c|c|}
\hline Gene & & Primer sequences & Size (bp) \\
\hline \multirow{2}{*}{ GAPDH } & $\mathrm{F}$ & 5'-CATGGCCTTCCGTGTTCCTAC-3' & \multirow{2}{*}{122} \\
\hline & $\mathrm{R}$ & 5’-TCAGTGGGCCCTCAGATGC-3' & \\
\hline \multirow{2}{*}{$\mathrm{COX}-2$} & $\mathrm{~F}$ & 5'-CTCAGCCATACAGCAAATCCTT-3' & \multirow{2}{*}{101} \\
\hline & $\mathrm{R}$ & 5'-GTCCGGGTACAATCGCACTTAT-3' & \\
\hline \multirow{2}{*}{ iNOS } & $\mathrm{F}$ & 5'-CCAGCCTGCCCCTTCAAT-3' & \multirow{2}{*}{104} \\
\hline & $\mathrm{R}$ & 5'-ATCCTTCGGCCCACTTCCT-3' & \\
\hline \multirow{2}{*}{ IL-1 $\beta$} & $\mathrm{F}$ & 5'-TGACGGACCCCAAAAGAT-3' & \multirow{2}{*}{122} \\
\hline & $\mathrm{R}$ & 5'-GTGATACTGCCTGCCTGAAG-3' & \\
\hline \multirow{2}{*}{ IL-6 } & $\mathrm{F}$ & 5'-CCGGAGAGGAGACTTCACAGAG-3' & \multirow{2}{*}{107} \\
\hline & $\mathrm{R}$ & 5'-TCATTTCCACGATTTCCCAGAG-3' & \\
\hline \multirow{2}{*}{$\mathrm{TNF} \alpha$} & $\mathrm{F}$ & 5'-AGGCACTCCCCCAAAAGATG-3' & \multirow{2}{*}{122} \\
\hline & $\mathrm{R}$ & 5'-CACCCCGAAGTTCAGTAGACAGA-3' & \\
\hline \multirow{2}{*}{ IL-10 } & $\mathrm{F}$ & 5'-GCTGGACAACATACTGCTAACCGACTC-3' & \multirow{2}{*}{141} \\
\hline & $\mathrm{R}$ & 5'-TCCTTGATTTCTGGGCCATGCTTCTCT-3’ & \\
\hline \multirow{2}{*}{ TGF- $\beta$} & $\mathrm{F}$ & 5'-GCTACCATGCCAACTTCTGTCTG-3’' & \multirow{2}{*}{106} \\
\hline & $\mathrm{R}$ & 5'-GAAGCGCCCGGGTTGTGTTGGTTGTAG-3' & \\
\hline
\end{tabular}


tion patterns showed that this strain was identified as $L$. paracasei $(99.9 \%$ ) according to the API database. In addition, the 16S rDNA gene sequence of $L$. casei MCL was deposited into GenBank under the accession number of JN974882. Identification of L. casei at the strain level is crucial for a variety of industrial applications, as it facilitates the tracking of specific strains with industrially-relevant properties.

The L. casei MCL isolated from raw milk and L. casei YIT 9029 were tested for their carbohydrate fermentation patterns using the API $50 \mathrm{CHL}$ kit. The results showed that the two strains used carbohydrates such as ribose, galactose, D-glucose, D-fructose, D-mannose, mannitol, sorbitol, N-acetyl glucosamine, esculin, salicin, D-cellobiose, maltose, lactose, saccharose, trehalose, D-turanose, gentiobiose, D-tagatose and gluconate (Table 2). D-adonitol, L-sorbose, amygdalin, and arbutin were only fermented by $L$. casei YIT 9029, and inulin and D-melezitose were only fermented by $L$. casei MCL.

Culture characteristics of $\boldsymbol{L}$. casei MCL in skim milk

Recently, $L$. casei strains have been widely used as a starter culture for yogurt and other fermented milk prod- ucts in the dairy industry. To use LAB as a starter culture, the viable count should be above $6 \mathrm{Log} \mathrm{CFU} / \mathrm{g}$ in order to supply a sufficient dairy dose (Samona and Robinson, 1991). Additionally, the $\mathrm{pH}$ should be between 4.2 and 4.4 in order to produce the organoleptic qualities of sourness and for the firm coagulum to be satisfactory (Narvhus, 1996). Among the 204 strains isolated from healthy adult feces and raw milk, only six strains were selected based on their consecutive culturability in 10\% skim milk. Finally, L. casei MCL isolated from raw milk was assessed for viable cell count, $\mathrm{pH}$, and titratable acidity. As shown in Fig. 1, the $\mathrm{pH}$ change of $L$. casei MCL was slightly higher than $L$. casei YIT 9029. After $16 \mathrm{~h}$, the $\mathrm{pH}$ of $L$. casei YIT 9029 rapidly decreased, while the final $\mathrm{pH}$ for $L$. casei MCL was found to be similar to that of L. casei YIT 9029 (Fig. 1). The viable cell count was $9 \mathrm{Log} \mathrm{CFU} / \mathrm{g}$ for both $L$. casei YIT 9029 and L. casei MCL. Based on these results, L. casei MCL was determined to have potential as a starter culture.

Effect of $L$. casei MCL on nitric oxide production NO is a suspected mediator in the development of diseases that are associated with chronic inflammation, including cancer. Practically every cell and many immu-

Table 2. Carbohydrate fermentation profiles of $L$. casei YIT 9029 and $L$. casei MCL*

\begin{tabular}{|c|c|c|c|c|c|}
\hline Carbohydrate & 9029 & MCL & Carbohydrate & 9029 & MCL \\
\hline Control & - & - & Esculin ferric citrate & + & + \\
\hline Glycerol & - & - & Salicin & + & + \\
\hline Erythritol & - & - & D-cellobiose & + & + \\
\hline D-arabinose & - & - & D-maltose & + & + \\
\hline L-arabinose & - & - & D-lactose & + & + \\
\hline D-ribose & + & + & D-melibiose & - & - \\
\hline D-xylose & - & - & D-saccharose & + & + \\
\hline L-xylose & - & - & D-trehalose & + & + \\
\hline D-adonitol & + & - & Inulin & - & + \\
\hline Methyl- $\beta$-D-xylopyranoside & - & - & D-melezitose & - & + \\
\hline D-galactose & + & + & D-raffinose & - & - \\
\hline D-glucose & + & + & Amidon & - & - \\
\hline D-fructose & + & + & Glycogen & - & - \\
\hline D-mannose & + & + & Xylitol & - & - \\
\hline L-sorbose & + & - & Gentiobiose & + & + \\
\hline L-rhamnose & - & - & D-turanose & + & + \\
\hline Dulcitol & - & - & D-lyxose & - & - \\
\hline Inositol & - & - & D-tagatose & + & + \\
\hline D-mannitol & + & + & D-fucose & - & - \\
\hline D-sorbitol & + & + & L-fucose & - & - \\
\hline Methyl- $\alpha$-D-mannopyranoside & - & - & D-arabitol & - & - \\
\hline Methyl- $\alpha$-D-glucopyranoside & - & - & L-arabitol & - & - \\
\hline N-acetylglucosamine & + & + & Potassium gluconate & + & + \\
\hline Amygdalin & + & - & Potassium 2-ketogluconate & - & - \\
\hline Arbutin & + & - & Potassium 5-ketogluconate & - & - \\
\hline
\end{tabular}

\footnotetext{
*The values indicate positive (+) and negative (-) fermentation for each strain.
} 

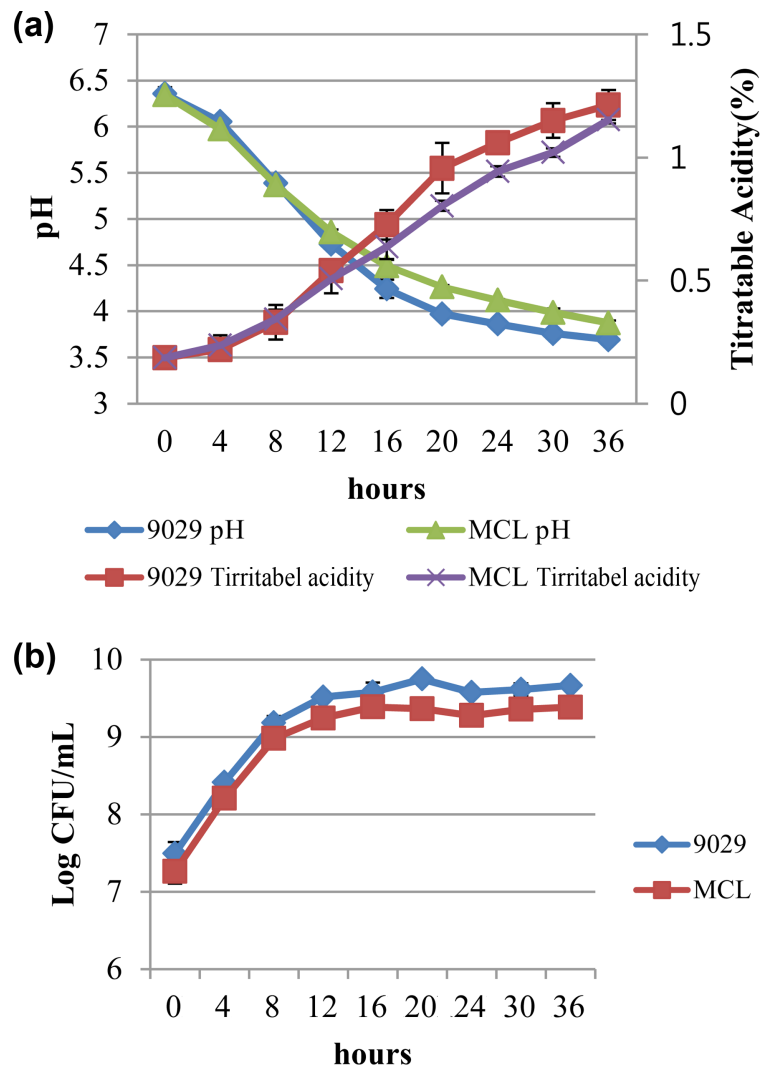

Fig. 1. Culture characteristics of $L$. casei MCL and $L$. casei YIT 9029 in $10 \%$ skim milk supplemented with $2 \%$ glucose. (a) $\mathrm{pH}$ and titratable acidity, (b) viable cell count of the bacteria.

nological parameters are modulated by NO (Cirino et al., 2006). NO also has several biological functions in many types of immune cells including the bactericidal effects of macrophages and signal transduction during inflammation (Jeong et al., 2010). The NO inhibiting rate of $L$. casei strains expressed relative rate (\%) compared with NO concentration of positive control. The positive control is only treated to LPS and the negative control is only treated to 1X PBS buffer in RAW264.7. As shown in Fig. 2, the rate of NO inhibition by $L$. casei MCL was significantly higher than that by the $L$. casei YIT 9029 strain. Moreover, $L$. casei MCL exhibited the highest inhibitory rate (\%) among the other L. casei strains (Fig. $2 b)$. The positive control (LPS-treatment sample) produced 21.91 $\mu \mathrm{M} N O$ and L. casei MCL produced $13.02 \mu \mathrm{M}$ NO (Fig. 2a). Therefore, we infer that $L$. casei MCL may exert an anti-inflammatory effect by inhibiting NO production.

Anti-inflammatory effect of cell components obtained from $L$. casei $\mathrm{MCL}$

The mRNA expression of pro-inflammatory cytokines (TNF- $\alpha$, IL-1 $\beta$, and IL-6) and enzymes involved in NO (a)

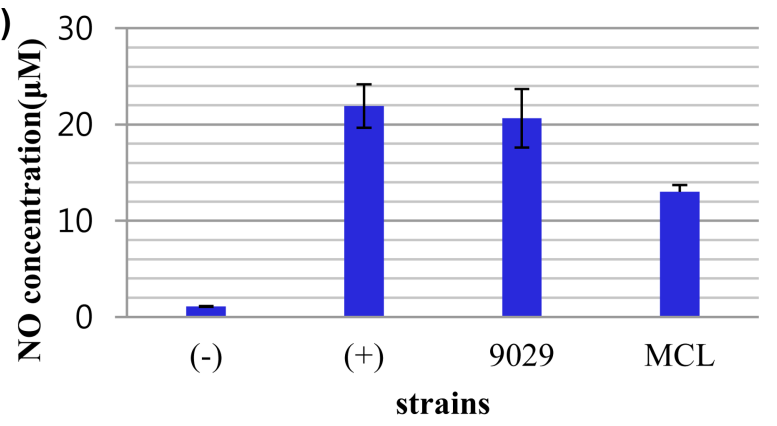

(b)

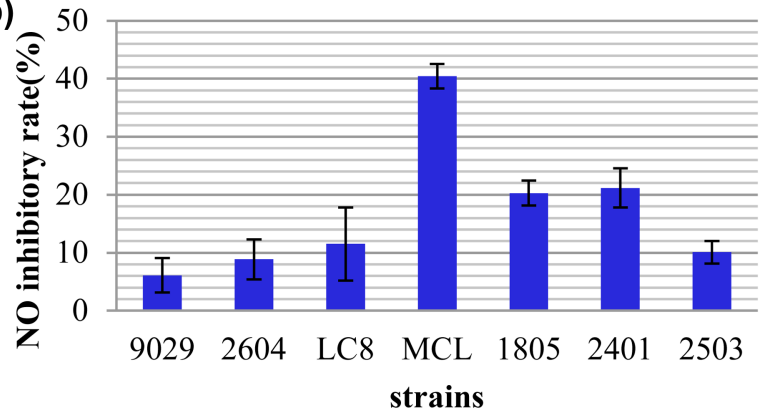

Fig. 2. (a) NO concentration $(\mu M)$ and (b) NO inhibitory rate (\%) in RAW 264.7 cells treated with the cellular components of seven $L$. case $i$ strains.

production (iNOS and COX-2) were determined using quantitative real-time PCR. iNOS is a key factor in the production of NO in macrophages stimulated by bacterial endotoxin (LPS), which in turn participates in the inflammatory response with pro-inflammatory cytokines such as TNF- $\alpha$, IL-1 $\beta$, and IL-6 (Nathan and Xie, 1994). IL-6 is a potent mitogenic polypeptide and stimulates cell proliferation in a various types of cells (Stein and Sutherland, 1998). Therefore, pro-inflammatory cytokines are important indicators of inflammation. According to Morotomi et al. (1996), the L. casi YIT 9029 strain has been demonstrated potential, when administered dietarily, to prevent cancer through its immunostimulating activity on experimentally-implanted tumors. Similarly, our results have also shown that $L$. casi YIT 9029 increases the expression of COX-2, iNOS, and IL-1 $\beta$ (data not shown). On the other hand, L. casei MCL was found to suppress all proinflammatory genes (Fig. 3). This indicates that $L$. casei MCL has the potential to enhance anti-inflammatory responses. All experiments were conducted in triplicate. Following stimulation with LPS for $24 \mathrm{~h}$, lower levels of pro-inflammatory cytokines were observed in RAW 264.7 cells from the $L$. casei MCL and LPS-treated sample compared with the sample treated with LPS only.

Stimulation with lipopolysaccharides causes an increase in the secretion of anti-inflammatory IL-10, which may respond to the local effects of inflammation (Yeganegi et 


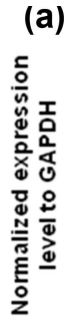

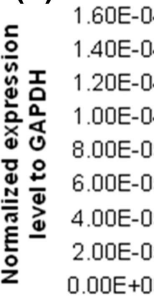

$\operatorname{cox}-2$

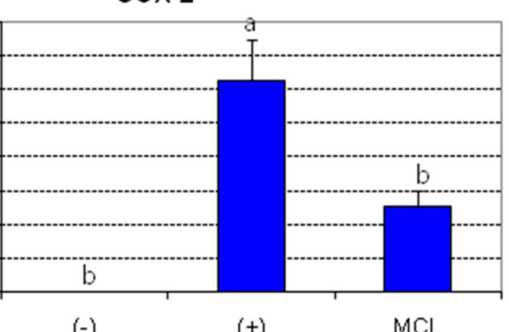

$(-)$

$(+)$

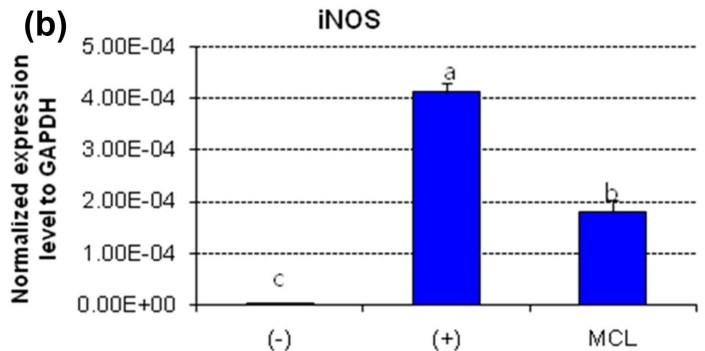

(c)

TNF- $\alpha$

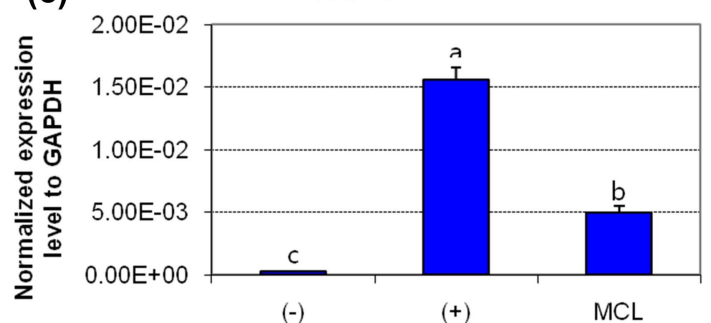

(d)

IL-1 $\beta$

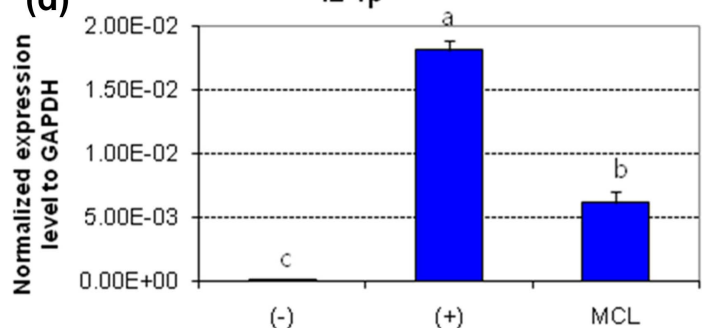

$(-)$

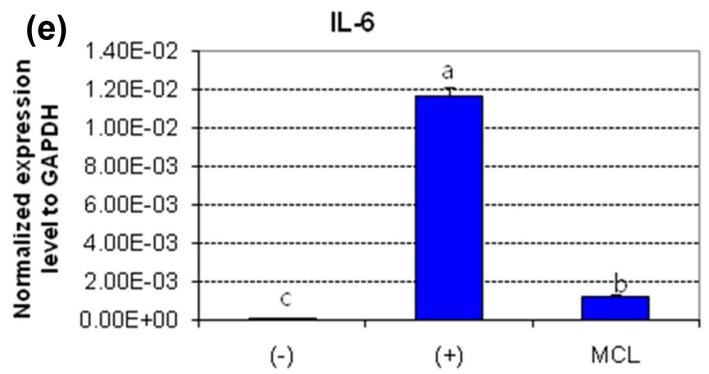

Fig. 3. mRNA expression levels of pro-inflammatory cytokines (a) COX-2, (b) iNOS, (c) TNF- $\alpha$, (d) IL-1 $\beta$ ), (e) IL-6 in RAW 264.7 cells treated with the cellular components of $L$. casei MCL. ${ }^{\mathrm{a}-\mathrm{c}}$ Means with different letters are significantly different $(p<0.05)$.

al., 2010). IL-10 has also been shown to inhibit IL-1 $\beta$, prostaglandin and TNF- $\alpha$ production in rhesus monkeys (Sadowsky et al., 2003). In addition, it was reported to act

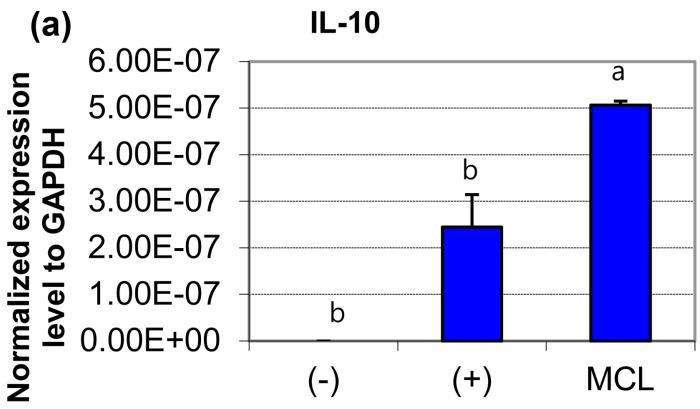

(b) TGF- $\beta$

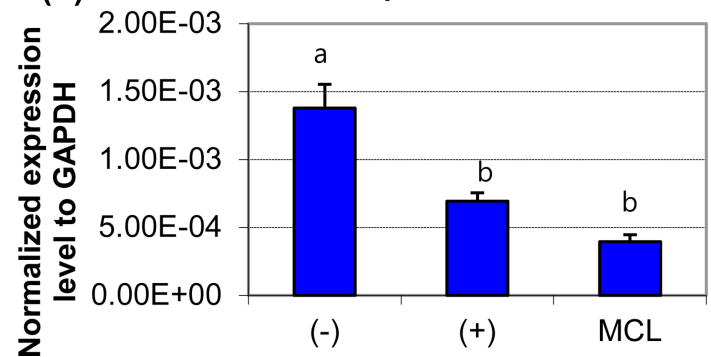

Fig. 4. mRNA expression levels of anti-inflammatory cytokines (a) IL-10, (b) TGF- $\beta$ in RAW 264.7 cells treated with the cellular components of $\boldsymbol{L}$. casei MCL. ${ }^{\mathrm{a}-\mathrm{c}}$ Means with different letters are significantly different $(p<0.05)$.

as a potent macrophage deactivator by blocking the induced synthesis of IL-6, IL-8, and COX-2 in human monocytes (Lee et al., 2009; Pena et al., 2003; Trushin et al., 2003).

Lactobacillus paracasei induces populations of regulatory CD4+ cells, which produce high levels of modulatory cytokines including IL-10 and TGF- $\beta$. As shown in Fig. 4, L. casei MCL up-regulated the level of IL-10, but did not have an effect on the expression of TGF- $\beta$. An increase in the secretion of the IL-10 anti-inflammatory cytokine by L. casei MCL may serve as a potential mechanism for preventing gastrointestinal infection and inflammation. Conclusively, L. casei MCL significantly decreased the secretion of pro-inflammatory cytokines such as IL- $1 \beta$, IL- 6 , and TNF- $\alpha$ and increased the secretion of anti-inflammatory cytokines such as IL-10.

\section{Anti-inflammatory effect of fermented milk from L. casei MCL}

To confirm the immune effects of milk fermented with the $L$. casei MCL strain, the strain was cultured in $10 \%$ skim milk supplemented with $2 \%$ glucose for $24 \mathrm{~h}$. The fermented milk containing $L$. casei MCL tended to reduce the secretion of particular pro-inflammatory cytokines such as COX-2, IL-6, and TNF- $\alpha$ in RAW 264.7 cells $(p<0.05)$ (Fig. 5) and TGF- $\beta$ to levels similar to those observed in the control sample $(p<0.05)$ (Fig. 6). How- 


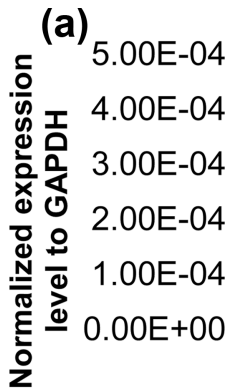

coX-2
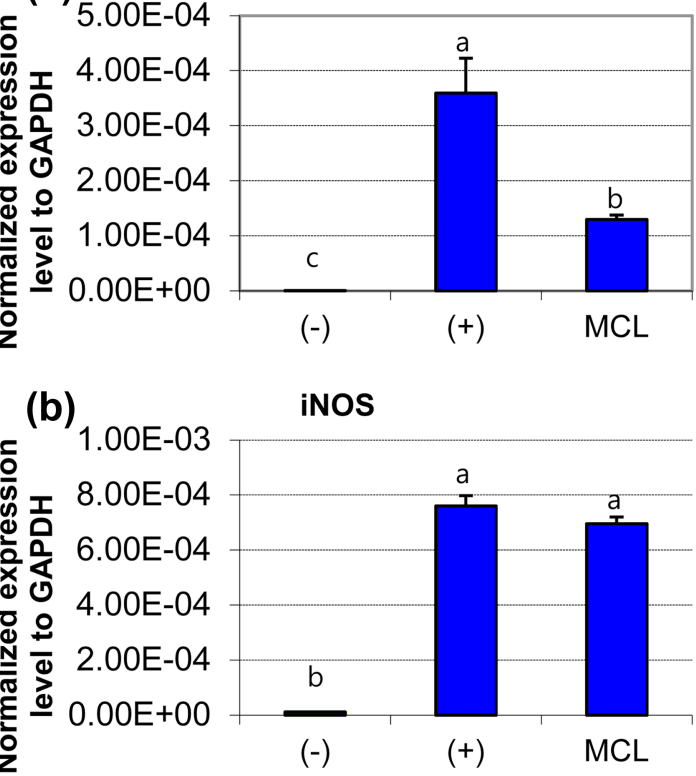

(c)

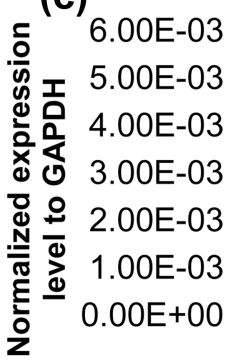

iNOS

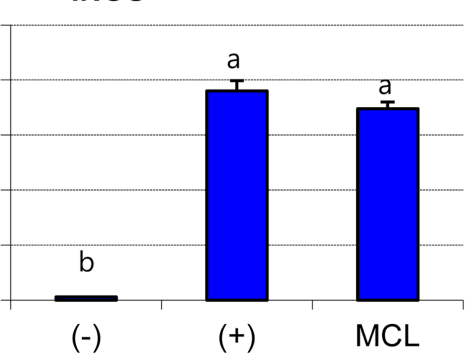

TNF- $\alpha$

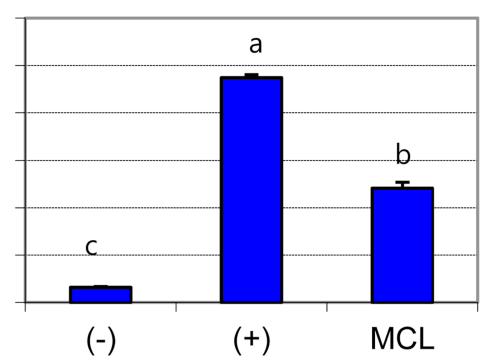

(d)

IL-1 $\beta$
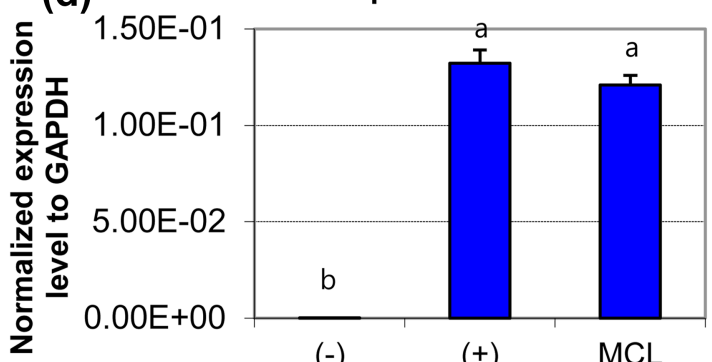

$(-)$

$(+)$

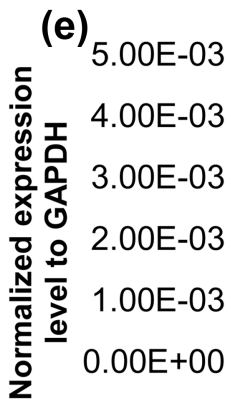

IL-6

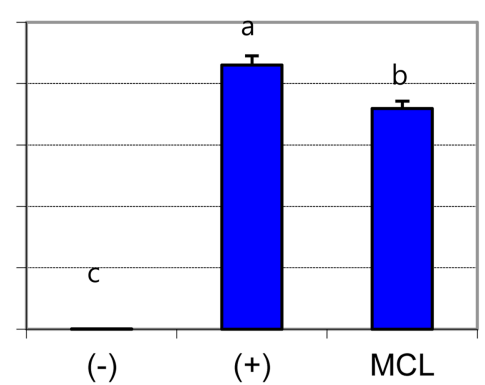

$(-)$

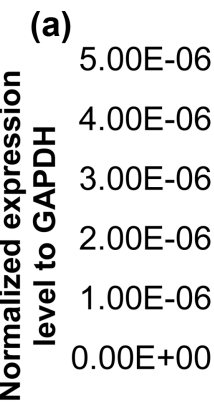

(b)

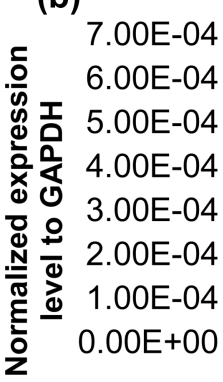

IL-10

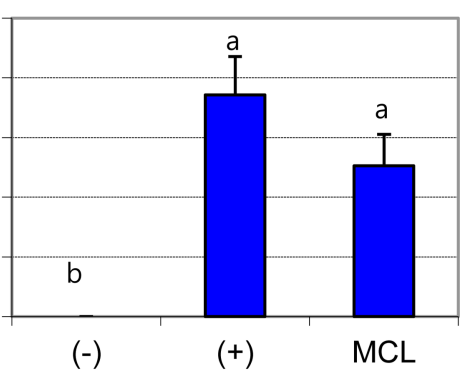

TGF- $\beta$

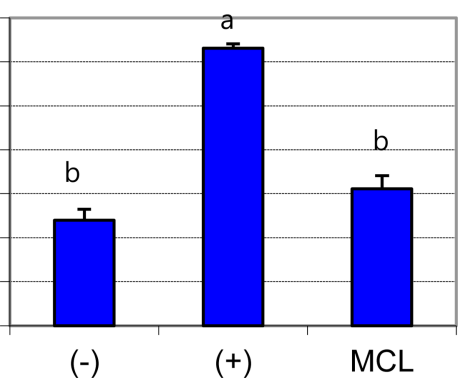

Fig. 6. mRNA expression levels of anti-inflammatory cytokines (a) IL-10, (b) TGF- $\beta$ in RAW 264.7 cells treated with milk fermented by $L$. casei MCL. ${ }^{\mathrm{a}, \mathrm{b}}$ Means with different letters are significantly different $(p<0.05)$.

ever, contrary to the bacterial component, milk fermented with the $L$. casei MCL was only able to repress the expression of COX-2, TNF- $\alpha$, IL-6 ( $p<0.05)$, and TGF- $\beta$ to levels similar to those observed in the control sample $(p<0.05)$. These results suggest that milk fermented by $L$. casei MCL may influence both specific and nonspecific immune responses. Lactobacillus rhamnosus GG downregulates the inflammatory response after milk consumption in milk-hypersensitive adults (Majamaa and Isolauri, 1997). Thus, the fermented milk from $L$. casei MCL may reduce the inflammatory response by decreasing the secretion of pro-inflammatory cytokines. It may also have the potential for application in immunomodulating fermented milk. Future studies are required to confirm the immunomodulating activity of $L$. casei MCL in vivo.

\section{Conclusions}

We investigated the effect of immunomodulating of $L$. casei strains on NO and cytokine expression in several experiments. This study confirms that when the macrophages were infected with LPS, L. casei MCL inhibited production of NO and proinflammatory cytokines. It is probably assume that $L$. casei MCL had immune regulation activity in macrophage. Inhibiting the substances related with inflammation reaction might show beneficial effect 
about gastrointestinal tract.

To get more insight into immunomodulating effect by probiotics, future studies combining cytokine gene expression and protein assay in disease models would be useful.

\section{Acknowledgements}

This research was supported by Chung-Ang University excellent freshman scholarship grants and the Basic Science Research Program through the National Research Foundation of Korea (NRF) funded by the Ministry of Education, Science and Technology (2011-0011903).

\section{References}

1. Cirino, G., Distrutti, E., and Wallace, J. L. (2006) Nitric oxide and inflammation. Inflamm. Allergy Drug Target 5, 115-119.

2. Coleman, J. W. (2001) Nitric oxide in immunity and inflammation. Int. Immunopharmacol. 1, 1397-1406.

3. de Waard, R., Garssen, J., Snel, J., Bokken G. C., Sako, T., Veld, J. H., and Vos, J. G. (2001) Enhanced antigen-specific delayed-type hypersensitivity and immunoglobulin G2b responses after oral administration of viable Lactobacillus casei YIT 9029 in Wister and Brown Norway rats. Clin. Diagn. Lab. Immun. 8, 762-767.

4. Food and Agriculture Organization of the United Nations. (2001) Health and nutritional properties of probiotics in food including powder milk with live lactic acid bacteria. (http:// www.who.int/foodsafety/publications/fs_management/en/ probiotics.pdf)

5. Fuller, R. (1993) Probiotic foods, current use and future developments. Int. Food Ingred. 3, 23-26.

6. Gilliland, S. E. and Walker, D. K. (1990) Factors to consider when selecting a culture of Lactobacillus acidophilus as a dietary adjunct to produce a hypocholesterolemic effect in humans. J. Dairy Sci. 73, 905-911.

7. Hanauer, S. B. (2002) New steroids for IBD: progress report. Gut 51, 182-183.

8. Henderson, B., Poole, S., and Wilson, M. (1996) Bacterial modulins: a novel class of virulence factors which cause host tissue pathology by inducing cytokine synthesis. Microbiol. Rev. 60, 316-341.

9. Ishikawa, H., Akedo, I., Otani, T., Suzuki, T., Nakamura, T., Takeyama, I., Ishiquro, S., Miyaoka, E., Sobue, T., and Kakizoe, T. (2005) Randomized trial of dietary fiber and Lactobacillus casei administration for prevention of colorectal tumors. Int. J. Cancer 116, 762-767.

10. Jeong, I. Y., Lee, H. J., Jin, C. H., Park, Y. D., Choi, D. S., and Kang, M. A. (2010) Anti-inflammatory activity of Stevia rebaudiana in LPS-induced RAW 264.7 cells. J. Food Sci. Nutr. 15, 14-18.

11. Kakizoe, T. (2000) Asian studies of cancer chemoprevention: latest clinical results. Eur. J. Cancer 36, 1303-1309

12. Kandler, O. and Weiss, N. (1986) Genus Lactobacillus Beijer- inck 1901. In: Bergey's manual of systematic bacteriology, Vol. 2. Sneath, P. H. A., Mair, N. S., Sharpe, M. E., and Holt, J.G. (eds) Williams and Wilkins, Baltimore, pp. 1209-1234.

13. Kato, I., Yokokura, T., and Mutai, M. (1984) Augmentation of mouse natural killer cell activity by Lactobacillus casei and its surface antigens. Microbiol. Immunol. 27, 209-217.

14. Lane, D. J. (1991) 16S/23S rRNA sequencing. In: Nucleic acid techniques in bacterial systematics. Stackebrandt, E. \& Goodfellow, M. (eds) John Wiley, Chichester, pp. 115-175.

15. Lee, J. H., Lee, B., Lee, H. S., Bae, E. A., Lee, H., Ahn, Y. T., Lim, K. S., Huh, C. S., and Kim, D. H. (2009) Lactobacillus suntoryeus inhibits pro-inflammatory cytokine expression and TLR-4-linked NF- $\mathrm{KB}$ activation in experimental colitis. Int. J. Colorectal Dis. 24, 231-237.

16. Lee, H. S., Han, S. Y., Bae, E. A., Huh, C. S., Ahn, Y. T., Lee, J. H., and Kim, D. H. (2008) Lactic acid bacteria inhibit proinflammatory cytokine expression and bacterial glycosaminoglycan degradation activity in dextran sulfate sodiuminduced colitic mice. Int. Immunopharmacol. 8, 574-580.

17. Macdonald, T. T. and Monteleone, G. (2005) Immunity, inflammation, and allergy in the gut. Science 307, 1920-1925.

18. Majamaa, H. and Isolauri, E. (1997) Probiotics: a novel approach in the management of food allergy. J. Allergy Clin. Immunol. 99, 175-185.

19. Matsubuchi, T., Takagi, A., Matsuzaki, T., Nagaoka, M., Ishikawa, K., Yokokura, T., and Yoshikai, Y. (2003) Lipoteichoic acids from Lactobacillus strains elicit strong tumor necrosis factor alpha-inducing activities in macrophages through Toll-like receptor 2. Clin. Diagn. Lab. Immun. 10, 259-266.

20. Matsumoto, S., Hara, T., Hori, T., Mitsuyama, K., Nagaoka, M., Tomlyasu, N., Suzuki, A., and Sata, M. (2005) Probiotic Lactobacillus-induced improvement in murine chronic inflammatory bowel disease is associated with the down-regulation of pro-inflammatory cytokines in lamina propria mononuclear cells. Clin. Exp. Immunol. 140, 417-426.

21. Menard, S., Candalh, C., Bambou, J. C., Terpend, K., CerfBensussan, N., and Heyman, M. (2004) Lactic acid bacteria secrete metabolites retaining anti-inflammatory properties after intestinal transport. Gut 53, 821-828.

22. Morotomi, M. (1996) Properties of Lactobacillus casei Shirota strain as probiotics. Asia Pacific J. Clin. Nutr. 5, 29-30.

23. Narvhus, J. (1996) Probiotiske bakterier-metabolisme in melk. Meieriposten 12, 341-343.

24. Nathan, C. and Xie, Q. W. (1994) Nitric oxide synthases: roles, tolls and controls. Cell 78, 915-918.

25. Pena, J. A. and Versalovic, J. (2003) Lactobacillus rhamnosus GG decreases TNF- $\alpha$ production in lipopolysaccharideactived murine macrophages by a contact-independent mechanism. Cell Microbiol. 5, 277-285.

26. Sadowsky, D. W., Novy, M. J., Witkin, S. S., and Gravett, M. G. (2003) Dexamethasone or interleukin-10 blocks interleukin-1 beta-induced uterine contractions in pregnant rhesus monkeys. Am. J. Obstet. Gynecol. 188, 252-236.

27. Sambrook, J., Fritsch, E. F., and Maniates, T. (1989) Molecular cloning: a laboratory manual, $2^{\text {nd }}$ ed. Cold Spring Harbor Laboratory Press, Cold Spring Harbor, N.Y. 
28. Samona, A. and Robinson. R. K. (1991) Enumeration of bifidobacteria in dairy products. J. Soc. Dairy Technol. 44, 6466.

29. Sanders, M. E. (1993) Effect of consumption of lactic cultures on human health. In: Advance in Food and Nutrition Research. Kinsella, J. (ed) Academic Press, San Diego, pp. 67-130.

30. Stein, B. and Sutherland, M. S. K. (1998) IL-6 as a drug discovery target. Drug Discov. Today 3, 202-213.

31. Stuehr, D. J. and Marlette, M. A. (1985) Mammalian nitrate biosynthesis: mouse macrophages produce nitrite and nitrate in response to Escherichia coli lipopolysaccharide. Proc. Nat'l. Acad. Sci. USA 82, 7738-7742.

32. Stuehr, D. J. and Marlette, M. A. (1987) Induction of nitrite/ nitrate synthesis in murine macrophages by BCG infection, lymphokines or interferon- $\gamma$. J. Immunol. 39, 518-525.

33. Trushin, S. A., Pennington, K. N., Carmona, E. M., Asin, S.,
Savoy, D. N., Billadeau, D. D., and Paya, C. V. (2003) Protein kinase $\mathrm{C} \alpha(\mathrm{PKC} \alpha)$ acts upstream of PK theta to activate

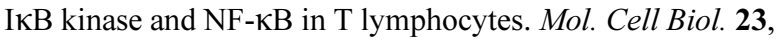
7068-7081.

34. Ulevitch, R. J. and Tobias. P. S. (1995) Receptor-dependent mechanisms of cell stimulation by bacterial endotoxin. Ann. Rev. Immunol. 13, 437-457.

35. Wai, P. Y. and Kuo, P. C. (2004) Nitric oxide and endotoxinmediated sepsis: the role of osteopontin. Gene Ther. Mol. Biol. 8, 501-508.

36. Yeganegi, M., Leung, C. G., Martins, A., Kim, S. O., Reid, G., Challis, J. R. G., and Bocking, A. D. (2010) Lactobacillus rhamnosus GR-1-induced IL-10 production in human placental trophoblast cells involves activation of JAK/STAT and MAPK pathways. Reprod. Sci. 17, 1043-1051.

(Received 2012.8.28/Revised 2012.10.11/Accepted 2012.10.25) 